\title{
Efficiency study of Environmentally Friendly inhibitors Neem leaf (Azadirachta indica) and Aloe vera (Aloe barbadensis) for Mild steel corrosion in $1 \mathrm{M} \mathrm{HCL}$
}

\author{
Dr.Jyoti G. Koliyar-Jatinder Das \\ Associate Professor and HOD, Department of Environmental Sciences, \\ SIES (Nerul) College of Arts, Science and Comerce, Neru, NaviMumbai, Maharashtra, India
}

\begin{abstract}
Corrosion is a natural process which converts a refined metal to a more chemically stable form, such as its oxides or hydroxides. It is the gradual destruction of materials is chemical and electrochemical reactions with their environment. In industries, corrosion occurs due to the use of solvents in the process, the most widely used agent is $\mathrm{HCL}$ and H2SO4. In present work, HCL is used as acidic medium to study the effect of neem leaf (Azadirachtaindica) and aloe vera( $($ Aloebarbedensis $)$ extracts as green inhibitor on the corrosion of mild steel immersed in $1 \mathrm{~N}$ HCL acid time interval of 1 hour, 3 hour and 5 hours at temperature of $30^{\circ} \mathrm{C}, 50^{\circ} \mathrm{C}$ and $70^{\circ} \mathrm{C}$. The results showed that the neem leaf and aloe vera has excellent inhibition efficiency and can be used as ecofriendly inhibitors as they are also cost effective and can reduce the use of chemical inhibitors.
\end{abstract}

Key words: Neem leaf, Aloe vera, Mild steel, Green inhibitor.

\section{INTRODUCTION:}

Corrosion is the critical attack of a material by reaction with its environment ${ }^{[1]}$. Corrosion is a process that occurs when a material deteriorates due to its interaction with the surrounding environment in which a electrochemical reaction consumes the material through oxidation ${ }^{[2]}$. The awareness of corrosion its periodic monitoring timely detection followed by maintenance and repair is very important especially for building structure and plants dealing with inflammable toxic chemicals ${ }^{[3]}$. The atmospheric corrosion comprises the attack on metals exposed to air, in India due to its climate the corrosion problems is more serious than that in cold countries ${ }^{[4]}$. The prevention of corrosion has become a serious and important area of research because of the growing need to implement effective and economical corrosion presentation method ${ }^{[8]}$. The recent trend is towards environment friendly inhibitors ${ }^{[5]}$. The natural organic plant extracts contain a variety of organic compounds for e.g. amino acid, alkaloids, steroids, flavonoids, proteins and tannins as a green alternative for toxic and hazardous compounds ${ }^{[1]}$. Mildsteel is one of the industrially important metals used under different conditions in Chemical and allied, and Oil and Gas industry in handling acid, and alkaline condition.

\section{MATERIALS AND METHODS:}

\section{Selection of plant species-}

Plant species-From different plants aloe vera extract and neem leaf extract was used to study the inhibition efficiency of mild steel coupons using 1N HCL solution. As these plants have medicinal properties and easily available and nontoxic to the environment and human.

\section{Preparation of aloe vera leaf extract-}

- $\quad$ The aloe vera leaf was squeezed so as to remove the gel inside.

- $\quad$ Stock solution was prepared by grinding the gel with 1N HCL solution.

- $\quad$ The resultant solution will be filtered and made volume upto $100 \mathrm{ml}$.

- $\quad$ From the stock solution of the extract different concentration of the inhibitor test solution ranging from 2 to $10 \% \mathrm{v} / \mathrm{v}$ will be made.

- $\quad$ The blank corrodent will be $1 \mathrm{~N}$ HCL solution and double distilled water will be used for the entire cleaning process. 
Vol. 8, Issue 10, October 2021

\section{Preparation of neem leaf extract-}

- $\quad$ Leaves of Azadirachta indica were collected and oven dries at $95^{\circ} \mathrm{C}$ for 2 hours, grounded and then sieved.

- $\quad$ Stock solution was prepared by refluxing $10 \mathrm{gm}$ of powder and $100 \mathrm{ml}$ 1N HCL for 3 hours and allowed to stand overnight. The resultant solution was filtered and the was made up to $100 \mathrm{ml}$.

- $\quad$ From this stock solution of the extract, different concentration of the inhibitor test solutions ranging from $2 \%$ to $10 \%$ v/v was made.

- $\quad$ The blank agent was $1 \mathrm{~N}$ HCL solution.

\section{Combined procedure-}

- $\quad$ After initial weighing of mild steel coupons that is specimens will be immersed in $100 \mathrm{ml}$ of $1 \mathrm{~N}$ HCL with and without different concentration of plant and dye solution at $30,50,70^{\circ} \mathrm{C}$ for 1,3 , and 5 hours.

- $\quad$ After incubation the specimens will be removed and washed with distilled water dried completely and then final weight will be taken.

- $\quad$ From the initial and final weight of the mild steel the weight loss, corrosion rate and the inhibition efficiency will be determined.

- $\quad$ The corrosion inhibition will be checked by using weight loss method.

\section{CALCULATION:}

Weight loss measurement method was used to calculate the inhibition efficiency of the plant extract.

Formula-

Inhibition efficiency $=\mathrm{W}_{0-} \mathrm{W} / \mathrm{W}_{0}$

Where, $\mathrm{W}_{0}$ is the difference in weight of mild steel coupons in blank solution

$\mathrm{W}$ is the difference in weight of mild steel dipped in different concentration of inhibitor.

\section{RESULTS AND DISCUSSIONS}

From the experiment, it was observed that the inhibition efficiency decreases at higher temperature that is $70^{\circ} \mathrm{C}$. The results showed that the suitable temperature for the plant extract was $50^{\circ} \mathrm{C}$.Azadirachta indica showed higher inhibition efficiency then Aloe barbedensis, it can control corrosion at a greater extend. At $30^{\circ} \mathrm{C}$, it showed good inhibition as the concentration was increased the efficiency was also increased it showed higher inhibition at $8 \%$ concentration at 5 hours of incubation and at $50^{\circ} \mathrm{C}$ it showed maximum inhibition at $10 \%$ concentration at 5 hours of incubation and very low corrosion rate. At $70^{\circ} \mathrm{C}$ it showed comparatively less inhibition it may be due to the higher temperature was not

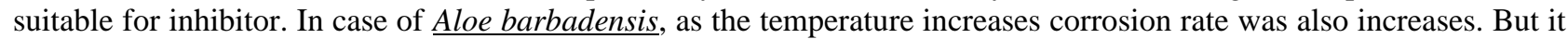
also showed low inhibition efficiency at $30^{\circ} \mathrm{C}$. Time also has effect on inhibitors activity. Therefore, controlling and decreasing the temperature can increase the inhibition efficiency of plant extract in acid solution of HCL. The suitable temperature for Azadirachta indica was $50^{\circ} \mathrm{C}$, at which it favours the excellent corrosion inhibition of mild steel.

Different concentration was used to study the effect of plant extract on mild steel at different temperature range of $30 \mathrm{C}, 50 \mathrm{C}$ and 70C. From the results it was observed that as the concentration of inhibitor increases the inhibition efficiency was also increases, it was also seen that the corrosion rate decreases. Thus it can be concluded that concentration thus affect the corrosion rate and inhibition efficiency the higher inhibition efficiency was seen at $8 \%$ concentration for Aloe barbadensis and $10 \%$ concentration for Azadirachta indica at 5 hours of incubation thus the use of higher concentration can decrease the corrosion rate at suitable temperature. At 1 hour of incubation the corrosion was high it may be due to that the inhibitor required more time to form a thin layer on the surface of the mild steel plates. It showed that the time also affect the inhibitor activity. The decrease in the corrosion rate can be the results of inhibitory effect of the plant extract present in the acid solution.

OBSERVATION TABLE: Comparison between Aloebarbadensis (species 1) and Azadirachtaindica (species 2)

TABLE NO.01:

\begin{tabular}{|c|c|c|c|c|c|c|}
\hline TEMPERATURE & \multicolumn{6}{|l|}{$30^{0} \mathrm{C}$} \\
\hline TIME & \multicolumn{2}{|l|}{1 HOUR } & \multicolumn{2}{|l|}{3 HOUR } & \multicolumn{2}{|l|}{5 HOUR } \\
\hline CONC(ML) & SPECIES 1 & SPECIES2 & SPECIES 1 & SPECIES 2 & SPECIES 1 & SPECIES 2 \\
\hline 2 & 1.21 & 1.75 & 8.10 & 89.47 & 42.46 & 55.22 \\
\hline 4 & 19.39 & 9.09 & 4.72 & 73.32 & 58.73 & 54.82 \\
\hline 6 & 10.90 & 9.09 & 6.08 & 75.86 & 73.80 & 49.40 \\
\hline 8 & 29.67 & 4.38 & 10.13 & 90.92 & 77.38 & 43.47 \\
\hline 10 & 26.06 & 1.75 & 14.86 & 98.72 & 74.60 & 86.56 \\
\hline
\end{tabular}


Vol. 8, Issue 10, October 2021

TABLE NO.02:

DOI: $10.17148 /$ IARJSET.2021.81006

\begin{tabular}{|l|l|l|l|l|l|l|}
\hline TEMPERATURE & \multicolumn{5}{l}{$50^{\circ} \mathrm{C}$} \\
\hline TIME & 1 HOUR & 3 HOUR & 5 HOUR \\
\hline CONC(ML) & SPECIES 1 & SPECIES 2 & SPECIES 1 & SPECIES 2 & SPECIES 1 & SPECIES 2 \\
\hline 2 & $32 \%$ & $\mathbf{5 8 . 8 2 \%}$ & $\mathbf{5 5 . 4 0 \%}$ & $\mathbf{9 0 . 2 1 \%}$ & $\mathbf{6 0 . 5 0 \%}$ & $\mathbf{7 4 . 0 7 \%}$ \\
\hline $\mathbf{4}$ & $\mathbf{4 0 \%}$ & $\mathbf{6 3 . 9 7 \%}$ & $\mathbf{4 4 . 5 9 \%}$ & $\mathbf{8 5 . 9 5 \%}$ & $\mathbf{6 6 . 5 0 \%}$ & $\mathbf{8 5 . 7 5 \%}$ \\
\hline $\mathbf{6}$ & $\mathbf{3 6 \%}$ & $\mathbf{6 3 . 9 7 \%}$ & $\mathbf{6 6 . 2 1 \%}$ & $\mathbf{7 5 . 7 4 \%}$ & $\mathbf{7 9 \%}$ & $\mathbf{9 0 . 3 1 \%}$ \\
\hline $\mathbf{8}$ & $\mathbf{4 8 \%}$ & $\mathbf{6 5 . 4 4 \%}$ & $\mathbf{6 6 . 2 1 \%}$ & $\mathbf{9 3 . 6 1 \%}$ & $\mathbf{8 1 \%}$ & $\mathbf{9 2 . 8 5 \%}$ \\
\hline 10 & $\mathbf{4 0 \%}$ & $\mathbf{6 6 . 1 7 \%}$ & $\mathbf{5 5 . 4 0 \%}$ & $\mathbf{9 3 . 6 1 \%}$ & $\mathbf{7 6 . 5 0 \%}$ & $\mathbf{9 8 . 5 2 \%}$ \\
\hline
\end{tabular}

TABLE NO.03:

\begin{tabular}{|c|c|c|c|c|c|c|}
\hline TEMPERATURE & \multicolumn{6}{|l|}{$7^{0} \mathrm{C}$} \\
\hline TIME & \multicolumn{2}{|l|}{1 HOUR } & \multicolumn{2}{|l|}{3 HOUR } & \multicolumn{2}{|l|}{5 HOUR } \\
\hline CONC(ML) & SPECIES1 & SPECIES 2 & $\begin{array}{r}\text { SPECIES } \\
1\end{array}$ & $\begin{array}{r}\text { SPECIES } \\
2\end{array}$ & $\begin{array}{r}\text { SPECIES } \\
1\end{array}$ & $\begin{array}{l}\text { SPECIES } \\
2 \%\end{array}$ \\
\hline 2 & $6.53 \%$ & $74.61 \%$ & $2.36 \%$ & $50.37 \%$ & $55.16 \%$ & $12.46 \%$ \\
\hline 4 & $10.35 \%$ & $73.35 \%$ & $10.22 \%$ & $53.33 \%$ & $36.57 \%$ & $0.72 \%$ \\
\hline 6 & $1.63 \%$ & $72.58 \%$ & $20.23 \%$ & $65.92 \%$ & $39.52 \%$ & $90.30 \%$ \\
\hline 8 & $17.71 \%$ & $76.39 \%$ & $33.43 \%$ & $94.81 \%$ & $20.45 \%$ & $97.20 \%$ \\
\hline 10 & $8.17 \%$ & $74.61 \%$ & $15.24 \%$ & $65.92 \%$ & $48.67 \%$ & $\mathbf{8 7 . 8 1 \%}$ \\
\hline
\end{tabular}

Aloe barbadensis The corrosion rate of mild steel increases as the concentration of the plant extract increases. But as the temperature increases the inhibition efficiency decreases. This is because the higher temperature is not suitable for the inhibitor to work efficiently. The highest corrosion was seen at $8 \%$ concentration of aloe vera extract at $50^{\circ} \mathrm{C}$.

Azadirachta indica The corrosion rate of mild steel increases with increase in concentration of plant extract. It has seen that the inhibitor work efficiently at $50^{\circ} \mathrm{C}$ temperature at $10 \%$ concentration. It was also showed that the higher temperature was not suitable for inhibitor.

For Aloe barbadensis leaf extract, the highest inhibition was seen at 5 hours of time interval. It was also observed that the inhibition was not stable at $70^{\circ} \mathrm{C}$ it may be due to the higher temperature was not suitable for inhibitor. The inhibition was increased as the time interval increases.

Azadirachta indica showed excellent inhibition at 5 hours of interval. It was also observed that the inhibitor required more time to make film on the surface of the mild steel plates.

\section{CONCLUSION:}

In the present study, Aloe barbedensis andAzadirachta indica leaf extract were used in 1N HCL solution to study and compare the effect of green inhibitors on mild steel. Mild steel plates were used to study the corrosion rate at different temperatures of $30^{\circ}, 50^{\circ}$, and $70^{\circ} \mathrm{C}$ at different time intervals of 1,3 and 5 hours.HCL was used as acidic medium with plant extract.

The extract of aloe vera and neem acts as good inhibitor for mild steel. In case of aloe vera extract the inhibition efficiency increases with increase in concentration and the maximum efficiency was seen at $8 \%$ concentration at $50{ }^{\circ} \mathrm{C}$ temperature. It was also showed that at higher temperature was not suitable for inhibitor as corrosion rate was increased and showed decrease in inhibition as compare to other temperature.

Azadirachta indica also showed excellent inhibition efficiency. The highest inhibition was seen at $10 \%$ concentration at $50^{\circ} \mathrm{C}$ temperature. As the concentration of plant extract increases the inhibition efficiency increases. The suitable temperature for neem leaf extract to work efficiently was found to be $50^{\circ} \mathrm{C}$ and $30^{\circ} \mathrm{C}$. This showed that the proper temperature and concentration does have effect on corrosion and inhibition activity of inhibitor.

Also while comparing these two plant extracts, Azadirachtaindica had higher inhibition efficiency compared to Aloebarbadensis. These plant extracts can be used by industries at the temperature where it shows higher inhibition efficiency. The adsorption of inhibition obeys Langmuir adsorption isotherm. The extract creates a thin protective layer over the mild steel strips thus protecting them from the attack of corrosive agent ${ }^{[1]}$. Thus it can be concluded that these plant extracts can be used widely as they are available easily and also they are non -toxic and safe thus protecting from any allergic reactions. They can be replaced by the artificial chemical organic and inorganic inhibitors which are toxic and harmful to the environment, as these are ecofriendly and cost effective and can be used in industrial process. 


\section{International Advanced Research Journal in Science, Engineering and Technology}

Vol. 8, Issue 10, October 2021

\section{DOI: 10.17148/IARJSET.2021.81006}

REFERENCES

1. Koliyar J.G* and Sheeba Aiman, comparative study and effect of plant extracts to inhibit corrosion on mild steel by using $1 \mathrm{~N}$ HCL j.environ. res.develop 9(3A),2015.

2. Vashi R.T* and Desai Krunal,Anisidine isomers as corrosion inhibitors for zinc in HCL J. environ, res. Develop, 9(2) 2014.

3. AlexenderP.Boichenko*'Artemv Kulikova ${ }^{1} \&$ M.GYashkarova , Studies in corrosion of mild steel in hydrochloric acid solutions in presence of various dye dyestuffs, J.envron.res.develop, 1(4),2000.

4. R.T Vashi H,KKadiya* and V.A. Champaneri, corrosion study of metals in rural atmosphere, J.environ.res.develop,3(1),2008.

5. J. Rosaline Vimala ${ }^{1 *}, A . L e e m a$ Rosa $^{1}, \mathrm{~S}$. Raja $^{2}$, Cassia auriculata extract as corrosion inhibitor for mild steel in acid medium, international journal of chemTech research ,3(4),2011.

6. R.Ananda ,LouiseSathiyanthan ${ }^{* 1}$ S.Maruthamutha et al ,corrosion inhibition of mild steel by ethanolic extract of ricinuscommunis leaves , 12 pp356-360 2005

7. Sanjay Kumar Sharma Ackmez Mudhoo Gargi Jain \&Essam Khamir, corrosion inhibition of neem (azadirachta indica) leaves extract as a green corrosion inhibitor for zinc in $\mathrm{H}_{2} \mathrm{SO}_{4}$, green chemistry letters \& reviews 1:2,47-51,2009.

8. Sunil J. Kulkarni, A review on studies and research on Corrosion\& its prevention, international journal of research and review, 2 (9) 2015. 